\title{
Problems in Performance Management of Enterprises in China
}

\author{
Li Lixia \\ Xijing University, Xi'an, Shaanxi, China
}

Keywords: enterprise; performance management; performance evaluation

\begin{abstract}
Performance management is one of important contents of human resource management, and plays an irreplaceable role in it. It is not only to have an understanding of performance, also to constantly improve enterprise operation, promote employees to actively create more benefits for enterprises and further improve the performance. Each enterprise is composed of talents in various fields. The performance management can control the entire process from recruitment to performance evaluation, strongly promoting each employee. Therefore, whether an enterprise can conduct well performance management decides whether the enterprise can develop in a long run to a great extent.
\end{abstract}

\section{Introduction}

Performance management has gradually become the focus of enterprises and plays an important role in the development of enterprises and the improvement of enterprise and employee performance. It, also an evaluation means for enterprises and employees, is to offer corresponding remuneration according to performance so that employees can actively contribute to the development of enterprises. However, at present, the lack of reasonability in the management of enterprises leads to problems such as the unreasonable performance evaluation and formalized management, which is the main factor hindering the development.

\section{The Definition and Basic Contents of Performance Management}

The object of performance management is the various factors influencing performance, which is a necessary work for each enterprise. The key is to reach agreement with the strategic goal of enterprise and to decide the specific procedures, and finally to improve the enterprise operation and obtain more profits. People in different times have different definition of performance management, and it is generally believed a system to manage enterprise and personal performance.

No matter management staff or employees shall play an important role in this system and cooperate each other to realize the ultimate goal of enterprise, that is, to improve performance. In this process, they should cooperate, not to pass an order in single direction, but to keep information mutual communication and give feedback times when problems occur. Management staff play a dominant role in the work, however, the core of work is still each normal employee, so the influence of employees is actually the greatest. Therefore, each link of management requires the participation of normal employees to constantly give feedback on corresponding information. It should be noticed that this work is throughout the entire operation and changes continuously according to actual situation so as to adapt to the status of enterprises. It is still required to establish fair compensation system to offer corresponding remuneration according to the actual performance of each employee, which can reflect the function of management and promote employees' enthusiasm for create profits.

\section{Problems in Performance Management of Enterprise}

\subsection{The incomplete performance management system}

Management is to relate enterprise performance to personal interests so that employees can actively produce more values. This is a systematical management, and performance evaluation is an 
important content. The evaluation relies on whether it can be comprehensive and play a positive influence on employees. The contents of evaluation shall reflect the contribution employees made for enterprises. Whereas, in many enterprises, evaluation is not reasonable, paying attention to basic contents such as attendance or absenteeism, and failing to show their performance in the work. The main cause is that the work of many employees cannot be evaluated quantitatively, such as business effect and work efficiency, which hinders the evaluation and leads to major mistakes, so it is unfair. It is also because the evaluation standard is not clear, lacking the combination of employees' many aspects, and the results are not reasonable with large impact of human factor. Thus, it is also necessary to clarify the standard. At the same time, management is not all about performance evaluation, so other management contents cannot be ignored. Some enterprises fail to have a clear understanding of performance, and fail to establish a complete system, so many work cannot be performed reasonably, which is common.

\subsection{The higher hindrance in performance management}

When enterprises carry out their work, they often lack the propaganda of the concept. Therefore, most of employees can consciously cooperate with the management work, but they do not have a clear understanding of the significance of this work. Some departments also lack the correct understanding. Therefore, many employees do not pay much attention to this. No matter what the results of the evaluation, it will not have any effect, so management cannot play a practical role. Some managers only imitate the management model of other excellent enterprises, simply repeat the process and do not understand its function. Enterprises only pay attention to the results of the evaluation, and do not communicate with employees in a timely manner. All requirements are transmitted to each employee in one direction, resulting in many problems in their work without feedback. Performance management should be two-way, with the cooperation between the management and employees to achieve the ultimate goal. Employees are the main factor affecting performance. Nowadays, few companies conduct distributed according to work on compensation, employees lack the enthusiasm to improve individual performance, because no matter how hard they work, they get the same reward.

\subsection{The formalized performance management}

Some enterprises only pay attention to the form of management, ignoring the positive impact that management can bring to the enterprise and its significance for future development. Many enterprises only work to manage performance, and they do not know that the essence of this work is to improve performance, not as a regular process, without specifically analyzing the current problems and the impact on the business. Some enterprises always set a goal that seems to be too big to be achieved, and take it as a means of motivation, but there is almost no substantial effect. Because of this phenomenon, employees lack a correct understanding of performance management, cannot actively cooperate and find their own defects and cannot make progress. Because managers do not pay much attention to this, some enterprises set a low goal, so that the goal is not the direction of efforts, but the reason for negative demotivation, and performance has always been at a low level. It is necessary to clarify that performance management is not just a procedure, but a practical work to improve enterprise operation. Therefore, enterprises cannot pay attention to current profits, but make plans for future. In this way, the significance of performance management can be clarified.

\subsection{The insufficient management personnel}

The high-quality management requires the participation of professionals. Whereas, many management staff are part-time, their professional field is not management, so it is difficult to ensure the high-quality management. This is mainly because management involves many contents, it is hard to complete with the efforts of single person, but a professional team. However, it takes more time and resources to build a team, and Chinese professional management staff have less experience, even some without experience, which increases the difficulty in the construction of a team. In addition, the management major in many colleges and universities fail to set courses 
related to performance management. They just organize some people together for simple training and they will be in charge of the management work. Management can be completed according to some rules, however, limited by the proficiency and standard, the entire quality shall be improved.

\section{Solutions to Problems in Performance Management}

\subsection{To correct the concept of performance management}

In terms of performance management, first of all, it is necessary to understand the importance of this work and complete it according to standard. Many enterprises obtain great achievements by carrying out performance management, so its reasonably implementation promotes the development of enterprises. However, limited by ideological concepts, many managers cannot recognize the importance of management, or mistakenly evaluation is the whole management. The evaluation can provide reference for enterprises operation, so that they can conclude their work and make progress through correction, and finally enhance the performance. Whereas, many managers have a misunderstanding. They perform evaluation regularly, however, formalized, to perform simply the procedures, which fails to play a practical role. Thus, in order to carry out well performance management, it is necessary to first ensure that the quality and ideas of managers need to reach the height they deserve, to clarify the importance of this work, and to constantly improve the vacancies in the current work. At the same time, when doing work, managers can also increase the promotion of correct concepts, so that more employees can have a deep understanding of it, and consciously complete their work, and promote the realization of enterprise goals.

\subsection{To clarify the core status of employee in performance management}

Performance management requires the cooperation of employees and management personnel. If one party pays less attention or does not actively cooperate, then the work will encounter a lot of resistance, and thus the ultimate goal of improving performance cannot be achieved. The enterprise is like a machine that constantly creates benefits, and the employees are the various components. Although the individual components are not enough to support the operation of the whole machine, they all play an irreplaceable role. Therefore, when carrying out management, it is necessary to clarify the dominant role of employees, pay more attention to employees, and take appropriate incentives to make them more active in their work, which will help improve the overall operation. It should be noted that it is not feasible to intervene too much on the work of the employees, otherwise it will have a negative impact on them. In performance evaluation, try not to interfere with other situations than the evaluation indicators. When there is a problem with the employee's working status, it is required to contact them in time, find out the cause of the problem, and take effective measures to solve it. This will enable employees to have the feeling of being recognized and valued by the enterprise, to relate enterprise performance to their own values, and to work hard to embody their values. In short, it is necessary to clarify the status of employees, give employees the rights they deserve, and minimize the interference in the work of employees in the evaluation, so as to ensure that management can consciously have a positive impact on the development of the enterprise.

\subsection{To establish a complete performance management system}

In addition to evaluation, performance management involves performance plan, implementation and management, result feedback and evaluation. They are related to each other. Only by completing each aspect well and accurately analyzing each factor that affects performance can we ensure that management plays a role. The premise of completion is under the constraints of perfect system, and there are still many loopholes in the current system, and there is no overall constraint on the work. Many problems in the current work are also caused by this. This is mainly due to the lack of a corresponding system for managers to carry out this work and the standards that can be used as a reference. In order to ensure that management can be carried out normally, it is necessary to continuously improve our existing system and related laws and regulations. At the same time, 
responsibility management should be done. The purpose is to enable everyone responsible for management to understand their responsibilities, to work harder and to make every job standardized, so that their values can be reflected in the work. When managers make mistakes and have an impact, they also need to be held accountable so that they can bear the consequences for their own mistakes. This will ensure that they can fully reflect on the reasons in the process of correcting their own mistakes and better perform in the future work, and urge themselves to regulate their behaviors.

\subsection{To introduce professional management personnel}

The reason why many problems occur in the management for enterprises is that there is no professional personnel to take charge of this work. Even if the system is relatively perfect, and it also requires various work contents, it may not be standardized due to the lower level of personnel. Therefore, enterprises should pay attention to the inspection of the level of internal management personnel, and also need to invest more resources to introduce more professionals to ensure that this work can be completed reasonably and promote the development of enterprises. Professionals need to have sufficient professional knowledge, high working ability and corresponding experience, and an accurate understanding of their own work, be able to clarify the impact of their work on the enterprise, and know what they should achieve. Professional managers can consciously optimize their own work processes according to the actual situation, and can consistently achieve their work goals and the enterprise goals. Compared with some of the part-time management personnel in the enterprise, they have higher advantages and concentration on their work. And the advantage of the introduction is that it does not require a large amount of resources to train employees, and more resources are saved. Of course, professionals may still have errors in their work to avoid problems.

\section{Conclusion}

At present, some enterprises still do not have a sound management system. Although relevant systems and institutions have already taken shape, they still need to be further explored according to the actual situation, so that this work can be done reasonably. After many years of practice, many problems have become more obvious and should be solved in a targeted manner. The management itself is quite special, and there is no special requirement for hardware, but it needs to be managed in combination with all aspects of the enterprise to ensure the rationality. It is also feasible take successful cases in foreign countries as reference to break through hindrances and finally enhance the performance by virtue of management.

\section{References}

[1] Li Xiaomei. On Human Resource Performance Management in Chinese Enterprises [J]. Human Resource Management, 2017, (29).

[2] Zhang Jianguo, Xu Wei. Performance System Design [M]. Beijing: Beijing University of Technology Press, 2003, (1).

[3] Yuan Haochen. Performance Management and the Effectiveness of Management [J]. China Collective Economy, 2019 (01).

[4] Zhang Tongle. Strategies of Performance Management from the Perspective of Strategic Human Resource Management [J]. Modern Economic Information, 2018 (10).

[5] Zhang Ping. The Construction of Human Resource Management System in Enterprise [J]. Enterprise Reform and Management, 2017 (08). 